\title{
Urban ecological security assessment for cities in the Beijing-Tianjin-Hebei metropolitan region based on fuzzy and entropy methods
}

\author{
Baolong Han, Hongxiao Liu, Rusong Wang* \\ State Key Laboratory of Urban and Regional Ecology, Research Centre for Eco-Environmental Sciences, Chinese Academy of Sciences, Shuangqing Road 18, \\ Haidian District, Beijing 100085, PR China
}

\section{A R T I C L E I N F O}

\section{Article history:}

Received 8 September 2014

Received in revised form

15 December 2014

Accepted 19 December 2014

Available online 13 January 2015

\section{Keywords:}

Urban ecological security

Beijing-Tianjin-Hebei metropolitan region

Fuzzy logic

Entropy weight

Pressure-state-response conceptual model

\begin{abstract}
A B S T R A C T
Based on the pressure-state-response conceptual model, we constructed the urban ecological security evaluation index system for 13 cities in the Beijing-Tianjin-Hebei metropolitan region from 2003 to 2014, where integrated development has occurred up to the national strategic level. The entropy-weight method was used to calculate the index weights to eliminate subjectivity. After the perfection and detailing of the increased half-ladder membership function and the confirmation of the membership standard of urban ecological security evaluation, the fuzzy synthetic evaluation method was used to calculate, analyze and evaluate the ranks of urban ecological security from 2003 to 2012 . The overall regional ecological security of the Beijing-Tianjin-Hebei metropolitan region increased during those 10 years. However, as expected for the obvious increase in the ecological state security level, neither the ecological pressure security nor the response security level significantly changed. In addition, urban social and economic indicators contributed more to the ecological security assessment than did the natural resource indicators and environmental indicators.
\end{abstract}

(c) 2015 Published by Elsevier B.V.

\section{Introduction}

Compared to a natural ecosystem, an urban ecosystem is characterized by high material and energy consumptions, high pollution and low natural resources, making it vulnerable and instable (Jiang and Chen, 2011; Liu et al., 2011b). There is no consensus on the concept of urban ecological security, and different connotations and denotations are derived from different dimensions of this concept (Gong et al., 2009; Tian and Gang, 2012). Badami and Ramankutty (2014) believed that, as urban agriculture and food security have an active relationship with food and nutrition security, income generation, and poverty alleviation, they are two key contents in the urban ecological security concept. Paton et al. (2014) recognized urban water supplement as one important aspect of urban security due to both its increased complexity and increased uncertainty under climate change. Jovanovic et al. (2010) suggested more attention be given to the energy system in an urban environment due to its complex structure with different types of resources and plenty of supplier and consumers. In addition, some researchers

\footnotetext{
* Corresponding author. Tel.: +86 10 62943807; fax: +86 1062943807.

E-mail addresses: baronhan@gmail.com (B. Han), michellewinter@126.com (H. Liu),wangrs@mail.rcees.ac.cn (R.Wang).
}

believe that urban ecological security should consider more social and economic factors (Michael et al., 2014). Ecological security means the absence of threats to human life, health, ease, basic rights, life ensure sources, necessary resources, and social sequence and the capability to acclimate environmental changes (Xiao et al., 2002). Combined with domestic and foreign academic viewpoints and studies on ecological security, the author believes that urban ecological security refers to the ecological factors and conditions in the natural-social-economic compound ecological system being able to support the sustainable development of the city. In addition, this concept has dynamic and relative connotations (Jia et al., 2004; Wang et al., 2011). As important as national defense security, economic security and food security, ecological security is the cornerstone and important component to national and regional security and development (Jia et al., 2004).

Related studies on ecological security have increased in recent years, mainly related to the connotation of the concept, the construction and management of regional ecological security, the strategic status and significance of ecological security and the monitoring technology and evaluation methods (e.g., index system and evaluation standard) of ecological security, etc. (Banos-González et al., 2014; Jiang and Chen, 2011; Li et al., 2010). Some scholars have performed exploratory research to evaluate ecological security. Although different methods have different foci, most of these 
Table 1

Ecological security evaluation index of the BTH region.

\begin{tabular}{|c|c|c|c|c|}
\hline Object layer & Project layer & Index layer & Unit & Impact \\
\hline \multirow{18}{*}{$\begin{array}{l}\text { Integrated ecological } \\
\text { security evaluation (ES) }\end{array}$} & \multirow{6}{*}{ Pressure layer $(P)$} & P1: domestic water-consumption per capita & $\mathrm{m}^{3} /$ capita & - \\
\hline & & P2: domestic electric consumption per capita & Kw h/capita & - \\
\hline & & P3: public green areas per capita & $\mathrm{m}^{2} /$ capita & + \\
\hline & & P4: industrial $\mathrm{SO}_{2}$ emissions intensity & $\mathrm{kg} / 10,000 \mathrm{RMB}$ & - \\
\hline & & P5: road pavement area per capita & $\mathrm{m}^{2} /$ capita & + \\
\hline & & P6: urban population density & $\mathrm{km}^{2} /$ capita & - \\
\hline & \multirow{6}{*}{ State layer $(S)$} & S1: built-up area greening coverage & $\%$ & + \\
\hline & & S2: construction land proportion in municipal district & $\%$ & - \\
\hline & & S3: natural population growth rate & $\%$ & - \\
\hline & & S4: per capita GDP & RMB/capita & + \\
\hline & & S5: per capita total investment in fixed assets & RMB/capita & + \\
\hline & & S6: announced unemployment rate & $\%$ & - \\
\hline & \multirow{6}{*}{ Response layer $(R)$} & $R 1$ : industrial solid waste utilization rate & $\%$ & + \\
\hline & & $R 2$ : sewage centralized treatment rate & $\%$ & + \\
\hline & & $R 3:$ tertiary industry proportion & $\%$ & + \\
\hline & & $R 4$ : proportion of fund for science \& education in GDP & $\%$ & + \\
\hline & & R5: number of beds in health care institutions & Unit per 10,000 capital & + \\
\hline & & $R 6$ : number of higher education students & Unit per 10,000 capital & + \\
\hline
\end{tabular}

methods are based on the pressure-state-response model (PSR) (Hua et al., 2011; Pei et al., 2010; Zhang et al., 2012). The basic procedures of the PSR are index selection, weight assignment, index system establishment and status value calculation. However, there is still no complete ecological security evaluation index system, evaluation standard, quantitative index or corresponding evaluation model (Li et al., 2014b; Tian and Gang, 2012). Few studies of urban ecological security have been non-PSR-based, such as the case study of Li and Xu (2010) with an ecological network analysis method and Gong et al. (2009)'s study using the cellular automata method. Both of these studies used Guangzhou, China, as their study cases. In addition, Li et al. (2014a) analyzed the ecological security of three regions in Inner Mongolia, China, with an ecological footprint index system. Kang and Xu (2010) discussed the feasibility of using the spatial-temporal balanced ecological carrying capacity to assess the ecological security and its regulation. These studies undoubtedly increase our understanding on ecological security; however, subjectivity and lack of objectivity in the process of weight determination are still problems. In addition, the calculation method is quantitative, making it unable to fully represent the fuzziness nature of ecological security (Chen et al., 2014; Jiang, 2011; Shen et al., 2015).

Based on the above considerations, this paper combined the PSR method, the fuzzy logic model and the entropy weight method in an empirical study for feasible urban ecological security evaluation modeling. The PSR method was used to establish an evaluation index system regarding the essence of ecological security. The Entropy method was used in the weighing assignment process to verify the objectivity of this modeling. The fuzzy method was used for the quantitative analysis to determine the fuzziness of urban ecological security. Finally, this method was used to evaluate the ecological security of the Beijing-Tianjin-Hebei (BTH) region from 2003 to 2012. BTH is famous for its strategic position as the area surrounding the capital. This paper analyzed both the temporal and spatial dynamics in this area. Not only was the study case novel, but both the research issue and combined method were original. The results are interesting, and some recommendations are given at the end.

\section{Method description}

\subsection{PSR conceptual model for urban eco-security index}

Various methods have been used for ecological security evaluation: exposure-response method, integrated index number method, ecological capacity analysis and some ecological models
(Wang and Cheng, 2003). After comparing the other methods, the authors recommended the pressure-state-response (PSR) concept model to establish the urban ecological security index due to its clear structure and logic. In addition, the analysis resulted in a PSR framework that can be easily understood and applied by decision makers in practice.

The concept of the environmental PSR index was proposed by Organization of Canadian Economic Cooperation and Development (OECD) and the United Nations Environment Program (UNEP) (Tong, 2000). The index system was established from three aspects that affect or are related to urban ecological security, i.e., the urban ecological pressure (the pressure from population growth and environmental resource assumption) the eco-environment state and the response (measures and policies that are adopted to solve ecoenvironmental issues) (Bai and Tang, 2010; Pei et al., 2010). With the help of expert consultation, frequency statistics and literatures investigation (Hua et al., 2011; Li et al., 2009; Theodoridou et al., 2012; Zhang et al., 2012), the evaluation index of the BTH region was established and is shown in Table 1. And the schematic of the cause-effect chain with indicators for the urban ecological security PSR framework was drawn in Fig. 1. In addition to the essence of the urban ecological security assessment, the choice of this index system was considered via other two aspects. The first aspect was the acceptability of the data. As there were changes in yearbooks during the study case period, some indicators did not have continuous data. The second aspect was the comparability of the data. Compared to scale indicators, percentage indicators are easily used in comparison between cities with different developed scales.

\subsection{Entropy method for index weights}

The key issue in evaluating ecological security (ES) from the 18 observed indicators was how to weigh each indicator with minimal subjectivity. The entropy-based weight method was used (Ludovisi, 2014; Zhang et al., 2006). In natural sciences, thermodynamic entropy is used to measure the disorder of a system. In social sciences, entropy information means the degree of uncertainty of a system. It is generally believed that the more entropy information one system has, the more balanced is its structure and the smaller is its difference (Chen et al., 2008; Han et al., 2014). From this perspective, the entropy information for each index was calculated, and smaller entropy means greater weight.

Using the calculation the weight of $P 1$ as an example.

Define $P m_{s i d}^{\prime}$ as the observed $P m$ value for sample $\operatorname{sid}$, and sid $=1$, $2,3, \ldots, n ; m=1,2,3,4,5,6$. The numbers of samples is $n$, which is the same in $S m_{\text {sid }}^{\prime}, R m_{\text {sid }}^{\prime}$. 


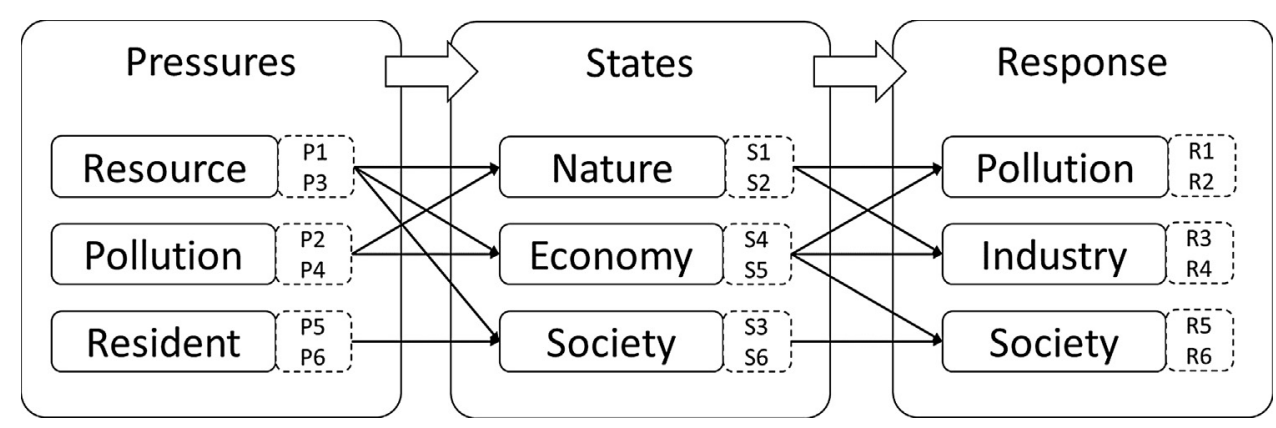

Fig. 1. Schematic of the cause-effect chain with indicators for the urban ecological security PSR framework.

Define $P 1_{\text {sid }}^{\prime \prime}$ as function (1), which is the same in $P m_{\text {sid }}^{\prime \prime}, S m_{\text {sid }}^{\prime \prime}, R m_{\text {sid }}^{\prime \prime}$

$P 1_{\text {sid }}^{\prime \prime}=\frac{P 1_{\text {sid }}^{\prime}}{\sum_{i=1}^{n} P 1_{i}^{\prime}}$

Define $e_{P 1}$ as the information entropy of indicator $P 1$ :

$e_{P 1}=-\frac{1}{\ln (n)} \sum_{i=1}^{n}\left(P 1_{i}^{\prime \prime} \times \ln \left(P 1_{i}^{\prime \prime}\right)\right), 0 \leq e_{P 1} \leq 1$

Define $d_{P 1}$ as the redundancy of $e_{P 1}$ :

$d_{P 1}=1-e_{P 1}$

Using the same method as above, $d_{P m}, d_{S m}, d_{R m}(m=1,2,3,4,5$, 6) can be calculated.

Because ES was composed of $d_{P m}, d_{S m}, d_{R m}(m=1,2,3,4,5,6)$, $W_{P 1}$ was defined as the weight of $P 1$

$W_{P 1}=\frac{d_{P 1}}{\sum_{m=1}^{6}\left(d_{P m}+d_{S m}+d_{R m}\right)}$

$W_{P}$ was defined as the weight of $P$ :

$W_{P}=\sum_{m=1}^{6} W_{P m}$

With the same calculation method as above, $W_{S}$ and $W_{R}$ can be calculated. The results of Index weight calculation are listed in Table 2.

\subsection{Fuzzy model for index evaluation}

The urban ecological security evaluation method evolved from a qualitative description in the early stage to today's quantitative model analysis, which mainly includes fuzzy synthesis, gray relation method, matter-element evaluation method, mutation progression method, landscape analysis, ecological footprint method, spatial statistical methods, etc. (Hu et al., 2008; Jiang, 2011; Yue et al., 2014). As the concept of "security" is fuzzy, i.e., not exact, there is no common idea about the exact threshold to divide safety and danger. Therefore, a fuzzy division for different security levels is required, and this paper chose the fuzzy synthesis evaluation method.

Fuzzy logic usually contains fuzzification, the application of the rule base to fuzzy data, the inference of fuzzy results and the defuzzification of fuzzy results. Fuzzification is a process that transforms the observed (real) data into a fuzzy form using a membership function that is defined by the feature of the target question. The rule base defines the relationship among the membership functions and the form of the resulting membership function. Defuzzification provides the real value from the resulting membership function (Icaga, 2007).
The establishment of the membership function is the key step in fuzzy evaluation. The study used up half of a trapezoid membership function and the security was divided into 1-5 scales in which 1 stands for insecure and 5 stands for secure. Because the selected evaluation index of ecological security has positive and negative effects, the membership function can be divided into positive and negative membership functions.

Using the positive impact indicator $P 3$ for example, its membership functions are functions (6) and (8). Defining $V_{x, i, P 3}$ as the membership of index $P 3$ for sample $x$ to security class $A_{i}, x P 3$ is the observed value of $P 3$ for sample $x$.

$V_{x, 1, P 3}=\left\{\begin{array}{ll}1 & x P 3 \leq A_{1, P 3} \\ \frac{x P 3-A_{2, P 3}}{A_{1, P 3}-A_{2, P 3}} & A_{1, P 3}<x<A_{2, P 3} \\ 0 & x P 3 \geq A_{2, P 3}\end{array}\right\}$

$V_{x, i, P 3}=\left\{\begin{array}{ll}0 & x P 3 \leq A_{(i-1), P 3} \\ \frac{x P 3-A_{(i-1), P 3}}{A_{i, P 3}-A_{(i-1), P 3}} & A_{(i-1), P 3}<x<A_{i, P 3} \\ \frac{x P 3-A_{(i+1), P 3}}{A_{i, P 3}-A_{(i+1), P 3}} & A_{i, P 3}<x<A_{(i+1), P 3} \\ 0 & x \geq A_{(i+1), P 3}\end{array}\right\}$

$V_{x, 5, P 3}=\left\{\begin{array}{ll}1 & x \leq A_{4, P 3} \\ \frac{x P 3-A_{4, P 3}}{A_{5, P 3}-A_{4, P 3}} & A_{4, P 3}<x<A_{5, P 3} \\ 0 & x \geq A_{5, P 3}\end{array}\right\}$

$A_{i, P m}(i=1,2, \ldots 5 ; m=1,2, \ldots, 6)$ is the threshold value of the conventional security class $A_{i}$ for indicator $P m$. Using the same method, the membership functions for the indicators $\mathrm{Sm}$ and $\mathrm{Rm}$ can be developed.

There is currently no standard in urban ecological security evaluation. Previous studies have mainly been based on the international, national, and local and industry rules of urban development and evaluation standards, such as environmental quality, public health standards issued by the national or international organization, environmental safety evaluation standard and regulation issued by various industries, governmental planning goals, regional background values and local standards. The analogical standard uses the ecosystem with no serious human interference as the standard of ecological security (Jiang, 2011; Li et al., 2014b; Pei et al., 2010; Tian and Gang, 2012). According to relevant standards of urban security evaluation, we developed an urban ecological security evaluation index system and classification standard for our research region (Table 3 ). 
Table 2

Entropy weights for ecological security evaluation index.

\begin{tabular}{|c|c|c|c|c|}
\hline Project layer & Weight & Index weight & & \\
\hline Pressure layer $(P)$ & 0.3338 & $\begin{array}{l}P 1: 0.0192 \\
P 4: 0.1162\end{array}$ & $\begin{array}{l}P 2: 0.0407 \\
P 5: 0.0209\end{array}$ & $\begin{array}{l}\text { P3: } 0.0581 \\
\text { P6: } 0.0787\end{array}$ \\
\hline State layer $(S)$ & 0.3841 & $\begin{array}{l}S 1: 0.0055 \\
S 4: 0.0821\end{array}$ & $\begin{array}{l}\text { S2: } 0.0715 \\
\text { S5: } 0.1243\end{array}$ & $\begin{array}{l}\text { S3: } 0.0602 \\
\text { S6: } 0.0405\end{array}$ \\
\hline Response layer $(R)$ & 0.2820 & $\begin{array}{l}R 1: 0.0277 \\
R 4: 0.0544\end{array}$ & $\begin{array}{l}R 2: 0.0151 \\
R 5: 0.0316\end{array}$ & $\begin{array}{l}R 3: 0.0213 \\
R 6: 0.1318\end{array}$ \\
\hline
\end{tabular}

Table 3

Conventional classes for ecological security evaluation index.

\begin{tabular}{|c|c|c|c|c|c|}
\hline \multirow[t]{2}{*}{ Index layer } & \multicolumn{5}{|c|}{ Conventional classes insecurity $\rightarrow$ security } \\
\hline & $A_{1, P m}$ & $A_{2, P m}$ & $A_{3, P m}$ & $A_{4, P m}$ & $A_{5, P m}$ \\
\hline$P 1$ : domestic water-consumption per capita & 65 & 55 & 40 & 30 & 20 \\
\hline P2: domestic electric consumption per capita & 1000 & 800 & 600 & 400 & 200 \\
\hline P3: public green areas per capita & 4 & 8 & 12 & 16 & 20 \\
\hline P4: industrial $\mathrm{SO}_{2}$ emissions intensity & 7 & 5.5 & 3 & 1.5 & 1 \\
\hline P5: road pavement area per capita & 5 & 10 & 15 & 20 & 30 \\
\hline P6: urban population density & 5000 & 4000 & 3000 & 2000 & 1000 \\
\hline$S 1$ : built up area greening coverage & 25 & 30 & 35 & 40 & 45 \\
\hline S2: construction land proportion in municipal district & 60 & 40 & 30 & 20 & 10 \\
\hline S3: natural population growth rate & 5 & 4 & 2.35 & 0.3 & 0.8 \\
\hline S4: per capita GDP & 10,000 & 30,000 & 50,000 & 80,000 & 120,000 \\
\hline S5: per capita total investment in fixed assets & 3000 & 5000 & 10,000 & 20,000 & 40,000 \\
\hline S6: announced unemployment rate & 10 & 8 & 6 & 4 & 2 \\
\hline$R 1$ : industrial solid waste utilization rate & 60 & 70 & 80 & 90 & 100 \\
\hline$R 2$ : sewage centralized treatment rate & 25 & 45 & 65 & 85 & 100 \\
\hline$R 3:$ tertiary industry proportion & 25 & 40 & 55 & 65 & 75 \\
\hline R4: proportion of fund for science \& education in GDP & 0.5 & 1 & 1.5 & 2 & 2.5 \\
\hline R5: number of beds in health care institutions & 30 & 50 & 70 & 90 & 100 \\
\hline$R 6$ : number of higher education students & 100 & 300 & 600 & 900 & 1200 \\
\hline
\end{tabular}

For sample $x$, its security membership for project layer pressure $(P)$ is $V_{x, P}^{\prime}$,

$V_{x, P}^{\prime}=\left[W_{P 1}, W_{P 2}, \ldots, W_{P 6}\right] \times\left[\begin{array}{lll}V_{x, 1, P 1} & \cdots & V_{x, 5, P 6} \\ \vdots & V_{x, i, P m} & \vdots \\ V_{x, 1, P 6} & \cdots & V_{x, 5, P 6}\end{array}\right]$

Using the same method as above, the memberships for the project layers state $\left(V_{X, S}^{\prime}\right)$ and response $\left(V_{X, R}^{\prime}\right)$ can be calculated.

For sample $x$, its membership for the object layer ecological security (ES) is $V^{\prime \prime}{ }_{X, E S}$,

$V_{x, E S}^{\prime \prime}=\left[W_{P}, W_{S}, W_{R}\right] \times\left[\begin{array}{c}V_{x, P}^{\prime} \\ V_{x, S}^{\prime} \\ V_{x, R}^{\prime}\end{array}\right]$

A calculation result of Beijing was served as examples in Tables 4 and 5, instead of the redundant total calculation results.

\section{Case study}

\subsection{Study area}

The BTH region is the hub spot of Bohai Sea in China, northeast Asia, and includes 13 cities: Beijing, Tianjin, Baoding, Langfang, Tangshan, Shijiazhuang, Xingtai, Handan, Cangzhou, Hengshui, Qinhuangdao, Chengde, and Zhangjiakou (Fig. 1). This region occupies $2.3 \%$ of the national territorial area, and its population accounts for $7.23 \%$ of the country's total population. This region is the largest and the most dynamic economic region in north China (Wang et al., 2014). As the population expanded speedily in recent years, a sharp deterioration happened to the natural environment in BTH region.
Several environment risks became much clearer, such as soil and water loss, land desertification, sandstorm and ecological degradation. Soil and water loss occurs mainly in the north and west of the Taihang mountains. And the land reclamation, overgrazing grassland happened in the north of Hebei contributed more to the sandstorm weather in Beijing and Tianjin.

\subsection{Data resource}

All of the data in this paper are from the China city statistical yearbook (2004-2013). We collected 18 indexes for 13 cities from 2004 to 2013, yielding a total of 130 samples and 2340 records. In the dataset, there were 23 missing values, and we used the mean value of the adjacent 2 years to replace the missing value.

\subsection{Results description}

(1) Cities' ecological pressure security rank in BTH region changed slightly from 2003 to 2012, except that Chengde sharply decreased in 2006. Only 5 of the 13 cities increased in this indicator, 1 city decreased, and 7 cities remained unchanged (Fig. 2). Upon a closer investigation, we found that Beijing, Tianjin and Cangzhou had increases in these indicators from 2003 to 2012 compared to those of the other 10 cities. At the end of 2012, the overall pressure security rank of 13 cities was at a medium level.

(2) Cities' ecological state security rank in the BTH region significantly changed from 2003 to 2012, except that 2 cities decreased slightly, 2 cities remained unchanged, and 9 of 13 cities obviously increased (Fig. 3). Tangshan, Handan, Zhangjiakou and Cangzhou increased by 4 security ranks (from 1 to 5) and Chengde by 3 ranks (from 2 to 5 ). At the end of 2012, the overall ecological state security rank of the 13 cities was at a high level. 
Table 4

Result of fuzzy membership calculation for Beijing's ecological security in 2012.

\begin{tabular}{|c|c|c|c|c|c|c|c|}
\hline \multirow[t]{2}{*}{ Indicators } & \multirow[t]{2}{*}{ Observed value } & \multicolumn{5}{|c|}{ Membership at different classes } & \multirow[t]{2}{*}{ Security rank } \\
\hline & & $A_{1}$ & $A_{2}$ & $A_{3}$ & $A_{4}$ & $A_{5}$ & \\
\hline$P 1$ & 52.74 & 0.0000 & 0.1508 & 0.8492 & 0.0000 & 0.0000 & 3 \\
\hline$P 2$ & 1288.14 & 1.0000 & 0.0000 & 0.0000 & 0.0000 & 0.0000 & 1 \\
\hline P3 & 48.45 & 0.0000 & 0.0000 & 0.0000 & 0.0000 & 1.0000 & 5 \\
\hline P4 & 0.89 & 0.0000 & 0.0000 & 0.0000 & 0.0000 & 1.0000 & 5 \\
\hline P5 & 7.53 & 0.5060 & 0.4940 & 0.0000 & 0.0000 & 0.0000 & 1 \\
\hline$P 6$ & 1006.40 & 0.0000 & 0.0000 & 0.0000 & 0.9936 & 0.0064 & 4 \\
\hline$S 1$ & 51.92 & 0.0000 & 0.0000 & 0.0000 & 0.0000 & 1.0000 & 5 \\
\hline$S 2$ & 11.86 & 0.0000 & 0.0000 & 0.0000 & 0.8140 & 0.1860 & 4 \\
\hline S3 & 6.80 & 1.0000 & 0.0000 & 0.0000 & 0.0000 & 0.0000 & 1 \\
\hline S4 & $87,475.00$ & 0.0000 & 0.0000 & 0.0000 & 0.1869 & 0.8131 & 5 \\
\hline S5 & $49,453.41$ & 0.0000 & 0.0000 & 0.0000 & 0.0000 & 1.0000 & 5 \\
\hline S6 & 0.60 & 0.0000 & 0.0000 & 0.0000 & 0.0000 & 1.0000 & 5 \\
\hline$R 1$ & 78.96 & 0.0000 & 0.8960 & 0.1040 & 0.0000 & 0.0000 & 2 \\
\hline$R 2$ & 83.00 & 0.0000 & 0.0000 & 0.9000 & 0.1000 & 0.0000 & 3 \\
\hline$R 3$ & 76.46 & 0.0000 & 0.0000 & 0.0000 & 0.0000 & 1.0000 & 5 \\
\hline$R 4$ & 4.63 & 0.0000 & 0.0000 & 0.0000 & 0.0000 & 1.0000 & 5 \\
\hline R5 & 71.38 & 0.0000 & 0.0000 & 0.0688 & 0.9312 & 0.0000 & 4 \\
\hline$R 6$ & 448.43 & 0.0000 & 0.4948 & 0.5052 & 0.0000 & 0.0000 & 3 \\
\hline Pressure & - & 0.0512 & 0.0132 & 0.0163 & 0.0782 & 0.1748 & 5 \\
\hline State & - & 0.0602 & 0.0000 & 0.0000 & 0.0736 & 0.2504 & 5 \\
\hline Response & - & 0.0000 & 0.0901 & 0.0852 & 0.0310 & 0.0758 & 2 \\
\hline Eco-security & - & 0.0512 & 0.0132 & 0.0163 & 0.0782 & 0.1748 & 5 \\
\hline
\end{tabular}

Table 5

Result of Beijing's ecological security membership and security rank from 2003 to 2012.

\begin{tabular}{|c|c|c|c|c|c|c|c|}
\hline \multirow[t]{2}{*}{ Years } & \multirow[t]{2}{*}{ Project indicators } & \multicolumn{5}{|c|}{ Membership at different classes } & \multirow[t]{2}{*}{ Security rank } \\
\hline & & $A_{1}$ & $A_{2}$ & $A_{3}$ & $A_{4}$ & $A_{5}$ & \\
\hline 2012 & $P$ & 0.0512 & 0.0132 & 0.0163 & 0.0782 & 0.1748 & 5 \\
\hline 2012 & $S$ & 0.0602 & 0.0000 & 0.0000 & 0.0736 & 0.2504 & 5 \\
\hline 2012 & $R$ & 0.0000 & 0.0901 & 0.0852 & 0.0310 & 0.0758 & 2 \\
\hline 2011 & $P$ & 0.0515 & 0.0136 & 0.0157 & 0.0000 & 0.2530 & 5 \\
\hline 2011 & $S$ & 0.0602 & 0.0000 & 0.0000 & 0.0628 & 0.2612 & 5 \\
\hline 2011 & $R$ & 0.0173 & 0.1068 & 0.0796 & 0.0025 & 0.0758 & 2 \\
\hline 2010 & $P$ & 0.0528 & 0.0122 & 0.0157 & 0.0000 & 0.2530 & 5 \\
\hline 2010 & $S$ & 0.0000 & 0.0000 & 0.1027 & 0.1013 & 0.1802 & 5 \\
\hline 2010 & $R$ & 0.0161 & 0.1106 & 0.0765 & 0.0030 & 0.0758 & 2 \\
\hline 2009 & $P$ & 0.0524 & 0.0153 & 0.0131 & 0.0000 & 0.2530 & 5 \\
\hline 2009 & $S$ & 0.0000 & 0.0091 & 0.1070 & 0.2080 & 0.0600 & 4 \\
\hline 2009 & $R$ & 0.0246 & 0.1036 & 0.0727 & 0.0054 & 0.0758 & 2 \\
\hline 2008 & $P$ & 0.0154 & 0.0557 & 0.0097 & 0.0000 & 0.2530 & 5 \\
\hline 2008 & $S$ & 0.0487 & 0.0114 & 0.0380 & 0.1093 & 0.1766 & 5 \\
\hline 2008 & $R$ & 0.0178 & 0.0933 & 0.0873 & 0.0291 & 0.0545 & 2 \\
\hline 2007 & $P$ & 0.0251 & 0.0365 & 0.0151 & 0.0042 & 0.2530 & 5 \\
\hline 2007 & $S$ & 0.0000 & 0.0022 & 0.0830 & 0.2088 & 0.0901 & 4 \\
\hline 2007 & $R$ & 0.0000 & 0.1126 & 0.0820 & 0.0268 & 0.0606 & 2 \\
\hline 2006 & $P$ & 0.0500 & 0.0115 & 0.0154 & 0.0756 & 0.1813 & 5 \\
\hline 2006 & $S$ & 0.0000 & 0.0000 & 0.0074 & 0.2597 & 0.1170 & 4 \\
\hline 2006 & $R$ & 0.0000 & 0.0860 & 0.0797 & 0.0969 & 0.0194 & 4 \\
\hline 2005 & $P$ & 0.0000 & 0.0228 & 0.1696 & 0.0045 & 0.1368 & 3 \\
\hline 2005 & $S$ & 0.0000 & 0.0634 & 0.0778 & 0.1006 & 0.2025 & 5 \\
\hline 2005 & $R$ & 0.0222 & 0.1094 & 0.0747 & 0.0466 & 0.0291 & 2 \\
\hline 2004 & $P$ & 0.0000 & 0.0299 & 0.0381 & 0.1291 & 0.1368 & 5 \\
\hline 2004 & $S$ & 0.0000 & 0.0290 & 0.1127 & 0.0829 & 0.2197 & 5 \\
\hline 2004 & $R$ & 0.0000 & 0.0888 & 0.1281 & 0.0107 & 0.0544 & 3 \\
\hline 2003 & $P$ & 0.0149 & 0.1563 & 0.0259 & 0.0000 & 0.1368 & 2 \\
\hline 2003 & $S$ & 0.0000 & 0.0085 & 0.1827 & 0.0162 & 0.1767 & 3 \\
\hline 2003 & $R$ & 0.0000 & 0.0694 & 0.1507 & 0.0075 & 0.0544 & 3 \\
\hline 2012 & ES & 0.0402 & 0.0298 & 0.0295 & 0.0631 & 0.1759 & 5 \\
\hline 2011 & ES & 0.0452 & 0.0347 & 0.0277 & 0.0248 & 0.2062 & 5 \\
\hline 2010 & ES & 0.0222 & 0.0353 & 0.0663 & 0.0398 & 0.1750 & 5 \\
\hline 2009 & ES & 0.0244 & 0.0378 & 0.0660 & 0.0814 & 0.1289 & 5 \\
\hline 2008 & ES & 0.0289 & 0.0493 & 0.0425 & 0.0502 & 0.1677 & 5 \\
\hline 2007 & ES & 0.0084 & 0.0448 & 0.0601 & 0.0892 & 0.1362 & 5 \\
\hline 2006 & ES & 0.0167 & 0.0281 & 0.0305 & 0.1524 & 0.1109 & 4 \\
\hline 2005 & ES & 0.0062 & 0.0628 & 0.1076 & 0.0533 & 0.1317 & 5 \\
\hline 2004 & ES & 0.0000 & 0.0461 & 0.0921 & 0.0779 & 0.1454 & 5 \\
\hline 2003 & ES & 0.0050 & 0.0750 & 0.1213 & 0.0083 & 0.1289 & 5 \\
\hline
\end{tabular}




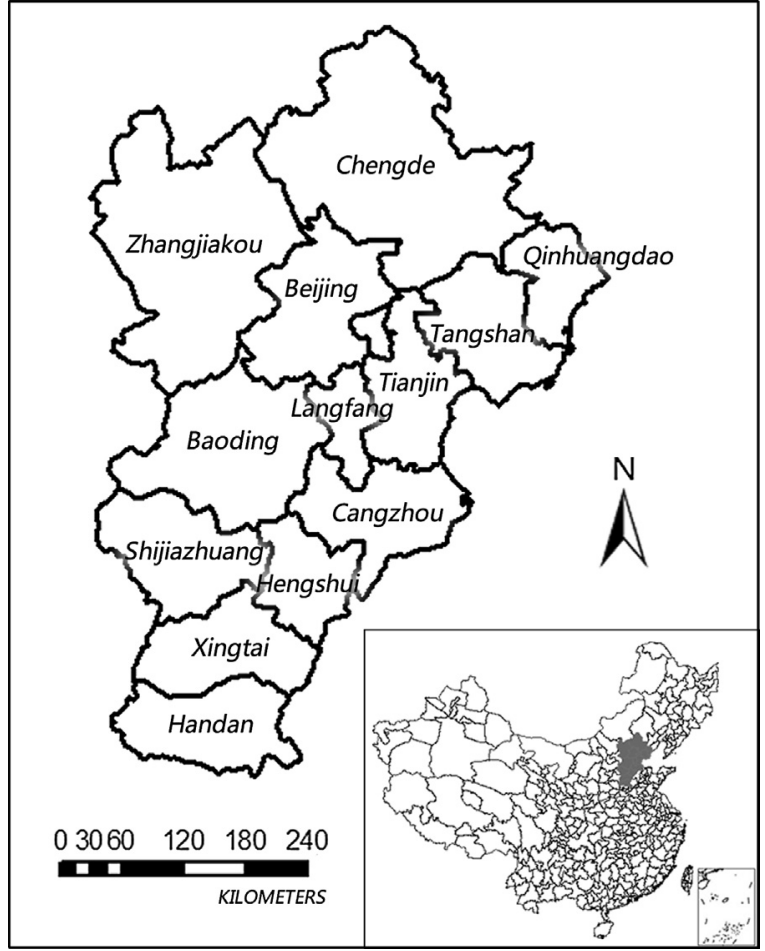

Fig. 2. Location and range of the BTH region, China.

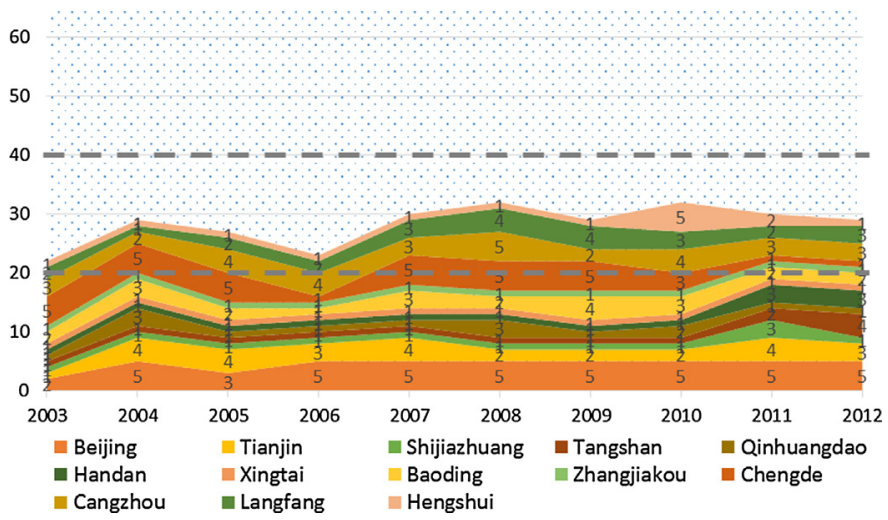

Fig. 3. Changes in the ecological pressure security for 13 cities in the BTH region from 2003 to 2012 .

(3) Cities' ecological response security rank in the BTH region changed less from 2003 to 2012. A total of 5 of the 13 cities increased by 1 rank during these years with 2 cities decreasing by 1 rank and 6 cities remaining unchanged (Fig. 4). At the end of 2012, the general ecological response security rank of the 13 cities was at a low level.

(4) Cities' comprehensive ecological security rank in the BTH region increased less from 2003 to 2012. Tianjin and Chengde increased by 4 ranks in this indicator. Together with Beijing, these cities maintained a high level. However, 7 of the 15 cities remained unchanged during these years (Fig. 5), and 8 of the 13 cities were still at the lowest level. At the end of 2012, the tendency of the ecological response security rank changed from a low level to a medium level compared to that of 2003. A closer inspection of Fig. 6 shows that the balance level of comprehensive ecological security among the 13 cities continued to increase, although it was still imbalanced. The number of cities at the high level increased from 1 to 3 , while the cities at the medium level increased from 0 to 1 .

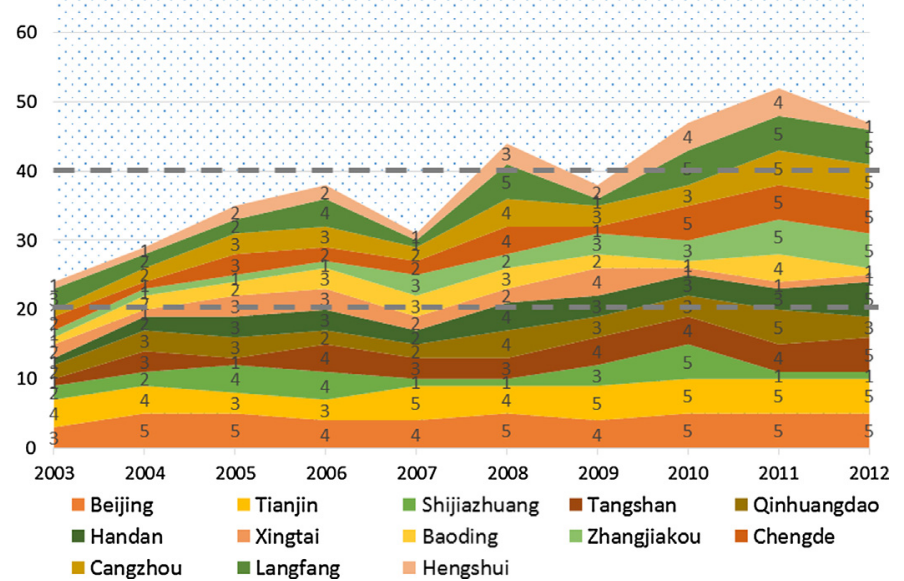

Fig. 4. Changes in the ecological state security for 13 cities in the BTH region from 2003 to 2012.

60

50

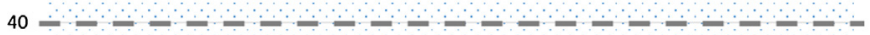

30

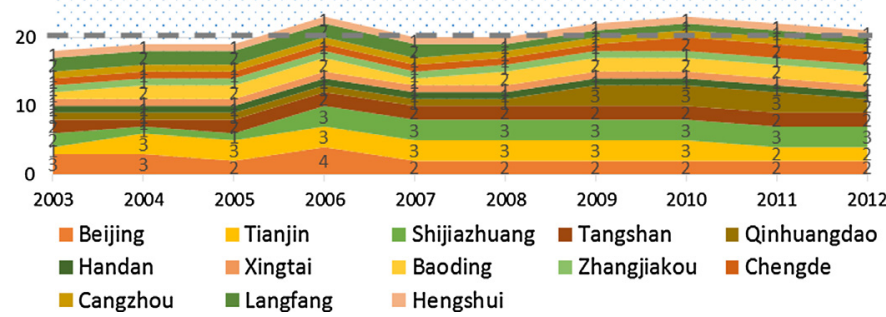

Fig. 5. Changes in the ecological response security for 13 cities in the BTH region from 2003 to 2012 .

60

50

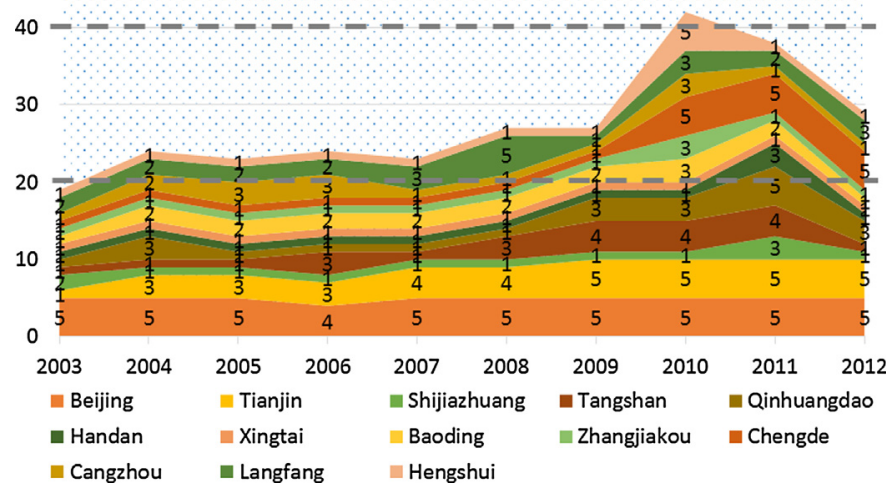

Fig. 6. Changes in the comprehensive ecological security for 13 cities in the BTH region from 2003 to 2012

\section{Discussion}

(1) Indicators that were directly related to the city's development contributed more to ecological security because that the 


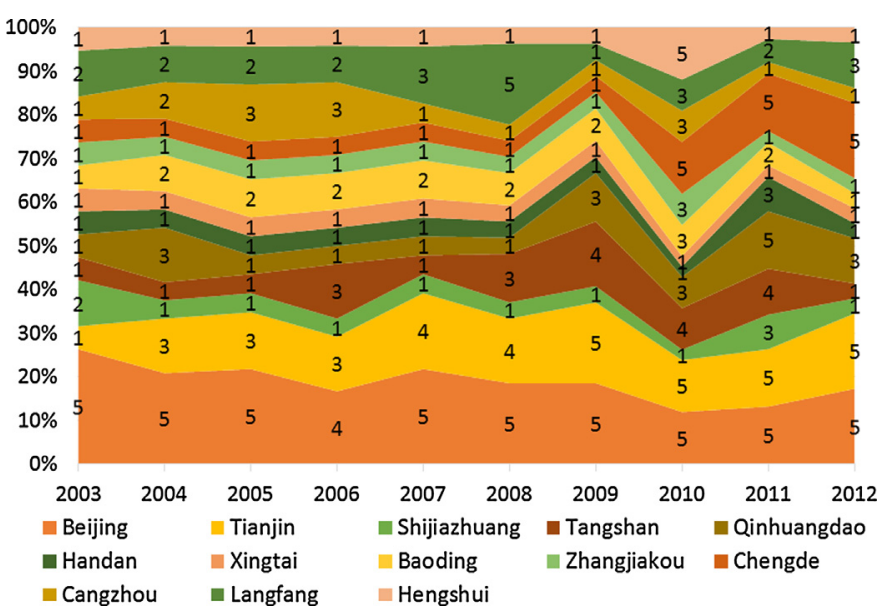

Fig. 7. Changes in the comprehensive ecological security balance for 13 cities in the BTH region from 2003 to 2012.

entropy method always provides those indicators that change more and faster and those with a greater weight. Compared to the natural resource indicators and environmental indicators, the city's social and economic indicators changed faster.

(2) Beijing and Tianjin performed well during these years. An indepth analysis of the structure of the index system and its weights can explain this result. The weight of indicator P4 (industrial $\mathrm{SO}_{2}$ emissions intensity) in Fig. 7(b) had the greatest contribution to the pressure indicator. Because China is working hard for industrial transfer, which transfers outmoded industry and traditional industry from developed areas to undeveloped areas, in recent years, cities around Beijing and Tianjin have received many heavy industrial companies, such as the Capital Iron Company (Yuan et al., 2013), which has significantly affected P4 between Beijing and its adjacent cities. Furthermore, $R 6$ (number of higher education students in 10 thousand in the capital) in Fig. 7(d) contributed the most to the response indicator. There is always a higher number of students in larger cities (because larger cities have more universities). In this way, Beijing and Tianjin performed better on both pressure indicator and response indicator than did the other surrounding cities. In addition, the results of Bai and Tang's case study on Tianjin (Bai and Tang, 2010) support this articles' results regarding the issue of Tianjin.

(3) The sharp changes that occurred in some cities in Hebei province during those years were reasonable, for instance, the pressure security rank of Chengde decreased from 5 (2005) to 1 (2006). This decrease occurred because there was an increase in the urban population in 2006, which increased the urban population density, decreased the road pavement area per capita, and finally decreased the pressure security. The increased pressure security rank of Hengshui was caused by decreased domestic water consumption per capita and domestic electric consumption per capita in 2010.

(4) Given a spatial view of the results of 4 different ecological security indicators, we found that the ecological security tended to improve in the north area of the $\mathrm{BTH}$ region, which was around Beijing and Tianjin (Fig. 8). There are 3 reasons for this result. First, the national government of the Capital Economy Region has been planned for years and contains 10 of the 13 cities in the BTH region (Liu et al., 2011a; Tian et al., 2014). This plan promoted the development of this area. Second, in recent years, Beijing and Tianjin have focused on environment improvement; many eco-towns, eco-zones and eco-counties were built in this area to support eco-development (Liu et al., 2014; Yu, 2014). Third, the past decade was a rapid urbanization decade for China. The development of cities always shares the radicalized spatial feature, in that the central areas develop better, and the edge areas develop less. The index for ecological

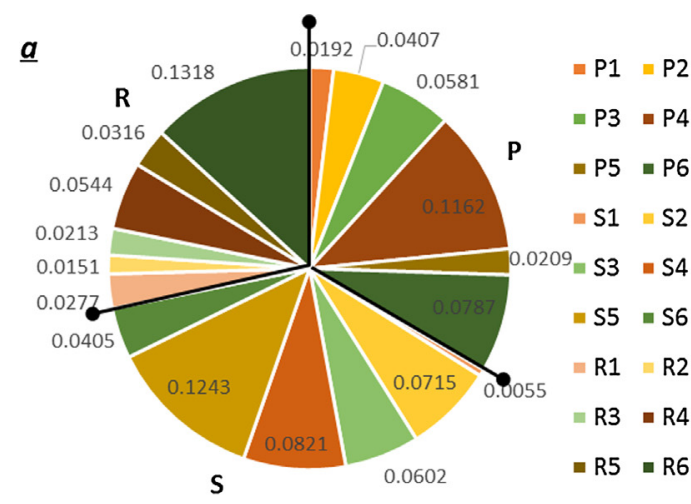

$\underline{c}$

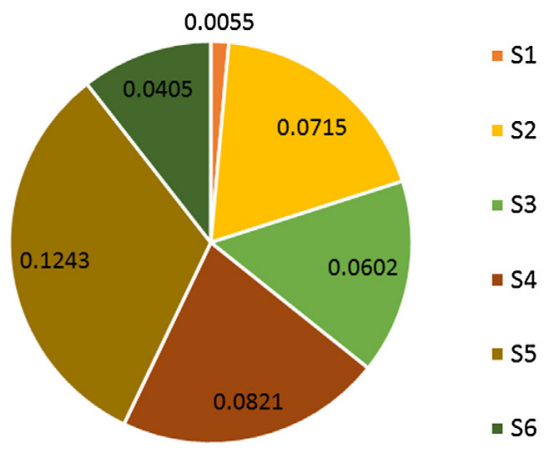

$\underline{b}$

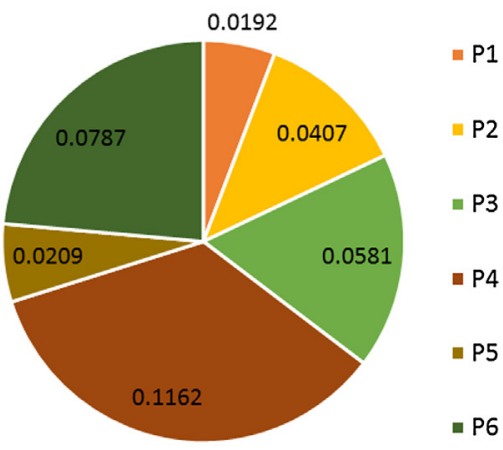

$\underline{d}$

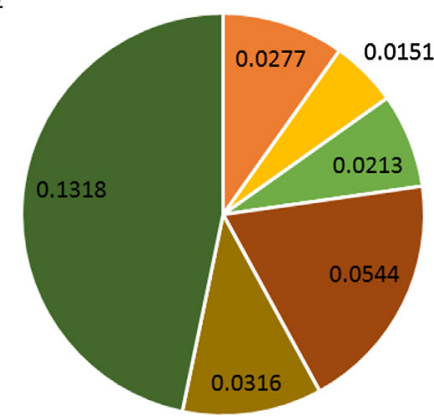

$\because \mathrm{R} 1$

$\varpi \mathrm{R} 2$

- R3

- $\mathrm{R} 4$

n5

Fig. 8. Entropy weights of the ecological security index. 


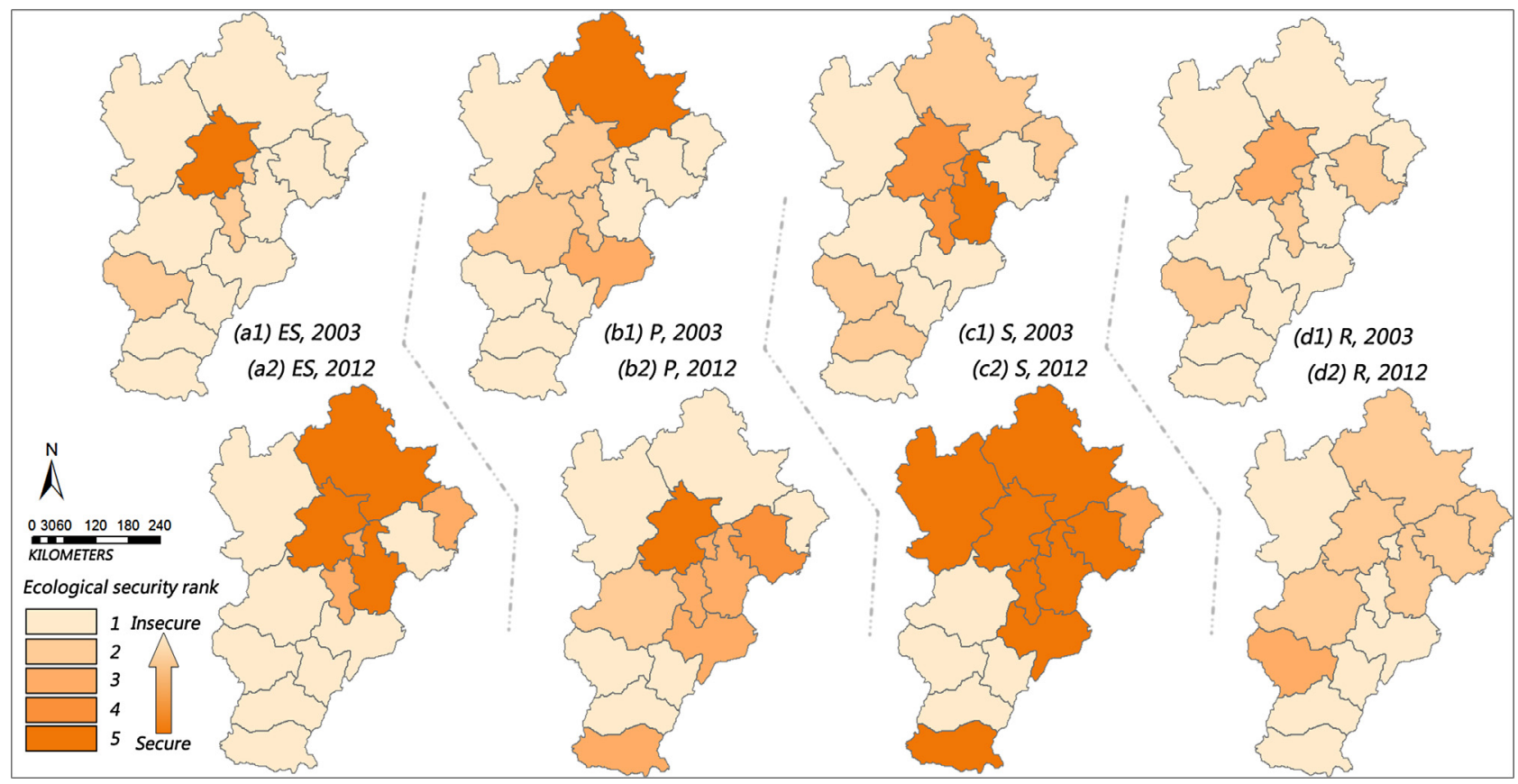

Fig. 9. Spatial changes in the ES rank for 13 cities in the BTH region from 2003 to 2012.

security assessment had many indicators for city development (Malczewski, 2009).

(5) An imbalance in urban ecological security still exists among Beijing, Tianjin and other Hebei cities. A comparison was made in Figs. 9 and 10 among Beijing, Tianjin and average cities in Hebei province. This comparison highlighted that the imbalance problem still existed among Beijing, Tianjin and Hebei. The increase rate of Hebei's urban ecological security is slower than that of the other two. In recent years, the BTH region actively implemented a strategy of sustainable development and conscientiously implemented a series of pollution prevention and ecological protection policies, such as a greening project for region around the capital, a returning farmland to forest project, and intensify the prevention and control of industrial pollution, enhancing the governance of the river basin water pollution. However, due to the historical reasons of imbalanced regional development, the ecological security problems of the BTH cities are still serious, for instance, the shortage of water resources and surface water pollution, the coexistence of poverty and ecological environment problems in same area, and pollution factories that are transferred from developed cities to underdeveloped cities, etc. To improve the level of BTH region's ecological security and balance, a few recommends are given as follows: (a) set up integrated management throughout the entire region; (b) add new ecological compensation methods, such as increased employment chances and compensation of high level human resources, to upgrade the traditional compensation ways, which are taxes and transfer payment; and (c) speed up the economic integration in the BTH region to improve the level of integration of environmental governance.

(6) There are still some problems that need to be solved in future research. There were fewer air quality indicators and environmental capacity indicators in the ecological security index due to a lack of statistic data. More air quality and extreme climate data need to be considered in relative research, as these issues are gaining increasing attention (Carter et al., 2014; Tehrani and Makhdoum, 2013). Moreover, both the ecological security index system and the threshold standard for fuzzy membership calculation lack of an explicit standard because ecological security is different in different climatic regions, even different in different periods of one region, weakening the global application of the index system and its parameters. However, the fuzzy-entropy method and pressure-state-response theory to assess the ecological security can be extended globally.

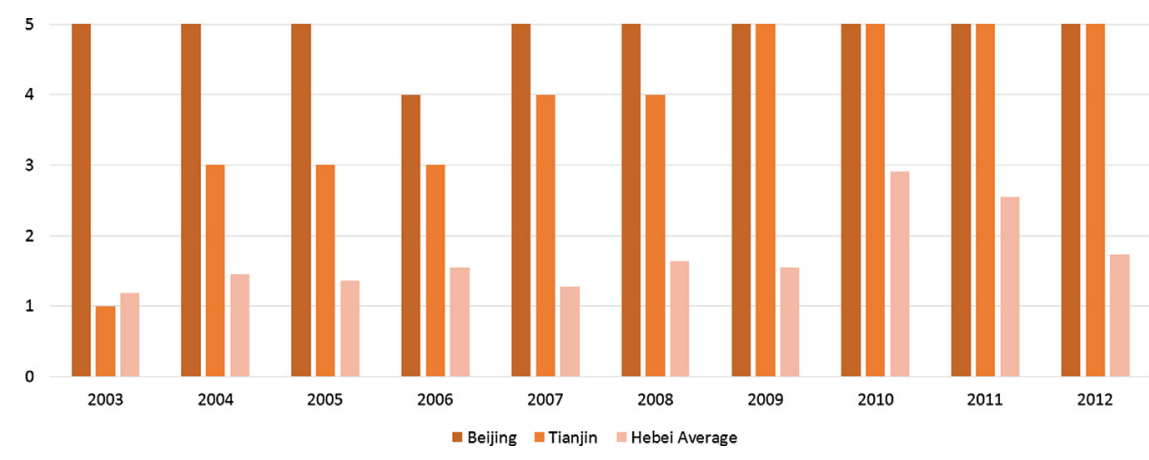

Fig. 10. Comparison among Beijing, Tianjin and average of cities in Hebei. 


\section{Conclusion}

(1) Beijing and Tianjin had a high ecological security rank from 2003 to 2012. The cities around Beijing and Tianjin improved obviously compared to those cities at the edge of the BTH region. Compared to that in 2003, the imbalance problem for cities' ecological security became less serious in 2012, but the problem still was not resolved. The further development of the Capital Economic Region may be one potential solution.

(2) Generally, both the ecological pressure security and the ecological response security in the BTH region changed slightly from 2003 to 2012. Ecological pressure security was at a medium rank at the end of 2012, while the ecological response security was at a low rank. However, the ecological state security improved from a medium rank to a high rank from 2003 to 2012, and the comprehensive ecological security improved from a low rank to a medium rank.

(3) According to the entropy weight method, indicators that were directly related to a city's social and economic development contributed more to the ecological security assessment.

\section{Acknowledgments}

The authors thank Jia, Juejie for his help on disposing part of the statistic data. This research was supported by the National Natural Science Foundation of China (No. 71033005).

\section{References}

Badami, M.G., Ramankutty, N., 2014. Urban agriculture and food security: a critique based on an assessment of urban land constraints. Glob. Food Secur., http://dx.doi.org/10.1016/j.gfs.2014.10.003.

Bai, X.R., Tang, J.C., 2010. Ecological security assessment of Tianjin by PSR model. Procedia Environ. Sci. 2, 881-887.

Banos-González, I., Martínez-Fernández, J., Esteve-Selma, M.Á., 2014. Dynamic integration of sustainability indicators in insular socio-ecological systems. Ecol. Model., http://dx.doi.org/10.1016/j.ecolmodel.2014.08.014.

Carter, J.G., Cavan, G., Connelly, A., Guy, S., Handley, J., Kazmierczak, A., 2015. Climate change and the city: building capacity for urban adaptation. Prog. Plan. 95, 1-66.

Chen, S.Z., Wang, X.J., Zhao, X.J., 2008. An attribute recognition model based on entropy weight for evaluating the quality of groundwater sources. J. China Univ. Min. Technol. 18, 72-75.

Chen, T., Jin, Y.Y., Qiu, X.P., Chen, X., 2014. A hybrid fuzzy evaluation method for safety assessment of food-waste feed based on entropy and the analytic hierarchy process methods. Expert Syst. Appl. 41, 7328-7337.

Gong, J.Z., Liu, Y.S., Xia, B.C., Zhao, G.W., 2009. Urban ecological security assessment and forecasting, based on a cellular automata model: a case study of Guangzhou, China. Ecol. Model. 220, 3612-3620.

Han, B.L., Wang, R.S., Tao, Y., Gao, H., 2014. Urban population agglomeration in view of complex ecological niche: a case study on Chinese prefecture cities. Ecol. Indic. $47,128-136$.

Hu, S.H., Wu, K.Y., Wang, J.Q., 2008. Study pre-warning of ecological security on basis of fuzzy optimize in Anhui province. J. Biotechnol. 136, S32.

Hua, Y.E., Yan, M.A., Limin, D., 2011. Land ecological security assessment for Bai autonomous prefecture of Dali based using PSR model with data in 2009 as case. Energy Procedia 5, 2172-2177.

Icaga, Y., 2007. Fuzzy evaluation of water quality classification. Ecol. Indic. 7, $710-718$.

Jia, L.Q., Ouyang, Z.Y., Zhao, T.Q., Wang, X.K., 2004. Ecological security assessment of an urban ecosystem. Ecol. Environ. 13, 592.

Jiang, M.M., Chen, B., 2011. Integrated urban ecosystem evaluation and modeling based on embodied cosmic energy. Ecol. Model. 222, 2149-2165.

Jiang, X., 2011. Urban ecological security evaluation and analysis based on fuzzy mathematics. Procedia Eng. 15, 4451-4455.

Jovanovic, M., Afgan, N., Bakic, V., 2010. An analytical method for the measurement of energy system sustainability in urban areas. Energy 35, 3909-3920.
Kang, P., Xu, L., 2010. The urban ecological regulation based on ecological carrying capacity. Procedia Environ. Sci. 2, 1692-1700.

Li, F., Liu, X.S., Hu, D., Wang, R.S., Yang, W.R., Li, D., Zhao, D., 2009. Measurement indicators and an evaluation approach for assessing urban sustainable development: a case study for China's Jining City. Landsc. Urban Plan. 90, 134-142.

Li, X., Tian, M., Wang, H., Wang, H., Yu, J., 2014a. Development of an ecological security evaluation method based on the ecological footprint and application to a typical steppe region in China. Ecol. Indic. 39, 153-159.

Li, X.B., Tian, M., Wang, r., Wang, H., Yu, H.J.J., 2014b. Development of an ecological security evaluation method based on the ecological footprint and application to a typical steppe region in China. Ecol. Indic. 39, 153-159.

Li, Y., Sun, X., Zhu, X., Cao, H., 2010. An early warning method of landscape ecological security in rapid urbanizing coastal areas and its application in Xiamen, China. Ecol. Model. 221, 2251-2260.

Li, Z., Xu, L., 2010. Evaluation indicators for urban ecological security based on ecological network analysis. Procedia Environ. Sci. 2, 1393-1399.

Liu, D.C., Li, N., Tan, X.C., Yang, X.O., Wang, L., Liu, J.B., 2011a. Study on energy strategy of Chinese capital region under the new national policy of reducing carbon dioxide emissions. Procedia Environ. Sci. 5, 2-11.

Liu, G.Y., Yang, Z.F., Chen, B., Zhang, Y., 2011b. Ecological network determination of sectoral linkages, utility relations and structural characteristics on urban ecological economic system. Ecol. Model. 222, 2825-2834.

Liu, W., Tian, J.P., Chen, L.J., 2014. Greenhouse gas emissions in China's eco-industrial parks: a case study of the Beijing economic technological development area. J. Clean. Prod. 66, 384-391.

Ludovisi, A., 2014. Effectiveness of entropy-based functions in the analysis of ecosystem state and development. Ecol. Indic. 36, 617-623.

Malczewski, J., 2009. Central place theory. In: Kitchin, R., Thrift, N. (Eds.), International Encyclopedia of Human Geography. Elsevier, Oxford, pp. 26-30.

Michael, F.L., Noor, Z.Z., Figueroa, M.J., 2014. Review of urban sustainability indicators assessment - case study between Asian countries. Habitat Int. 44, 491-500.

Paton, F.L., Dandy, G.C., Maier, H.R., 2014. Integrated framework for assessing urban water supply security of systems with non-traditional sources under climate change. Environ. Model. Softw. 60, 302-319.

Pei, L., Du, L.M., Yue, G.J., 2010. Ecological security assessment of Beijing based on PSR model. Procedia Environ. Sci. 2, 832-841.

Shen, L.Y., Zhou, J.Y., Skitmore, M., Xia, B., 2015. Application of a hybrid Entropy-McKinsey matrix method in evaluating sustainable urbanization: a China case study. Cities 42, 186-194.

Tehrani, N.A., Makhdoum, M.F., 2013. Implementing a spatial model of Urban Carrying Capacity Load Number (UCCLN) to monitor the environmental loads of urban ecosystems. Case study: Tehran metropolis. Ecol. Indic. 32, 197-211.

Theodoridou, I., Papadopoulos, A.M., Hegger, M., 2012. A feasibility evaluation tool for sustainable cities - a case study for Greece. Energy Policy 44, 207-216.

Tian, G.J., Qiao, Z., Gao, X.L., 2014. Rural settlement land dynamic modes and policy implications in Beijing metropolitan region, China. Habitat Int. 44, 237-246.

Tian, J.Y., Gang, G.S., 2012. Research on regional ecological security assessment. Energy Procedia 16 (Part B), 1180-1186.

Tong, C., 2000. Review on environmental indicator research. Res. Environ. Sci. 13, 53-56.

Wang, G.X., Cheng, G.D., 2003. Several problems in ecological security assessment research. J. Appl. Ecol. 14, 1551-1556.

Wang, R.S., Li, F., Hu, D., Larry Li, B., 2011. Understanding eco-complexity: socialeconomic-natural complex ecosystem approach. Ecol. Complex. 8, 15-29.

Wang, S.J., Ma, H.T., Zhao, Y.B., 2014. Exploring the relationship between urbanization and the eco-environment-a case study of Beijing-Tianjin-Hebei region. Ecol. Indic. 45, 171-183.

Xiao, D.N., Chen, W.B., Guo, F.L., 2002. On the basic concepts and contents of ecological security. Chin. J. Appl. Ecol. 13, 354-358.

Yu, L., 2014. Low carbon eco-city: new approach for Chinese urbanisation. Habitat Int. 44, 102-110.

Yuan, G.L., Sun, T.H., Han, P., Li, J., 2013. Environmental geochemical mapping and multivariate geostatistical analysis of heavy metals in topsoils of a closed steel smelter: Capital Iron and Steel Factory, Beijing, China. J. Geochem. Explor. 130, 15-21.

Yue, W.C., Cai, Y.P., Rong, Q.Q., Li, C.H., Ren, L.J., 2014. A hybrid life-cycle and fuzzyset-pair analyses approach for comprehensively evaluating impacts of industrial wastewater under uncertainty. J. Clean. Prod. 80, 57-68.

Zhang, X.C., Ma, C., Zhan, S.F., Chen, W.P., 2012. Evaluation and simulation for ecological risk based on energy analysis and pressure-state-response model in a coastal city, China. Procedia Environ. Sci. 13, 221-231.

Zhang, Y., Yang, Z.F., Li, W., 2006. Analyses of urban ecosystem based on information entropy. Ecol. Model. 197, 1-12. 